Pyatkova, K., Chen, A.S., Djordjević, S., Butler, D., Vojinović, Z., Abebe, Y.A., Hammond, M., 2019. Flood Impacts on Road Transportation Using Microscopic Traffic Modelling Techniques, in: Simulating Urban Traffic Scenarios, Lecture Notes in Mobility. Springer, Cham, pp. 115-126. DOI: $10.1007 / 978-3-319-33616-9 \_8$

\title{
Flood Impacts on Road Transportation Using Microscopic Traffic Modelling Technique
}

\author{
Katya Pyatkova, Albert S. Chen, Slobodan Djordjević, David Butler, Zoran \\ Vojinović, Yared A. Abebe, Michael Hammond
}

\begin{abstract}
This paper proposes a novel methodology for modelling the impacts of floods on traffic. Often flooding is a complex combination of various causes (coastal, fluvial and pluvial). Further, transportation systems are very sensitive to external disturbances. The interactions between these two complex and dynamic systems have not been studied in detail so far. To address this issue, this paper proposes a methodology for a dynamic integration of a flood model (MIKE FLOOD) and a microscopic traffic simulation model (SUMO). The flood modelling results indicate which roads are inundated for a period of time. The traffic on these links will be halted or delayed according to the flood characteristics - extent, propagation and depth. As a consequence, some of the trips need to be cancelled; some need to be rerouted to unfavorable routes; and some are indirectly affected. A comparison between the baseline and a flood scenario yields the impacts of that flood on traffic, estimated in terms of lost business hours, additional fuel consumption, and additional $\mathrm{CO}_{2}$ emissions. The proposed methodology will be further developed as a workable tool to evaluate the flooding impact on transportation network at city scale automatically.
\end{abstract}

Keywords: microscopic traffic modelling, road networks, traffic disruption, model integration, flood modelling, flood impacts

\author{
K. Pyatkova $\cdot$ A. S. Chen $\cdot$ S. Djordjević $\cdot$ D. Butler \\ Centre for Water Systems, University of Exeter , Exeter, United Kingdom \\ Email: \{K.Pyatkova, A.S.Chen, S.Djordjevic, D.Butler\}@exeter.ac.uk
}

Z. Vojinović $\cdot$ Y. A. Abebe · M. Hammond

UNESCO-IHE, Institute for Water Education, Delft, The Netherlands

Email: \{Z.Vojinovic, Y.Abebe, M.Hammond\}@unesco-ihe.org 
Pyatkova, K., Chen, A.S., Djordjević, S., Butler, D., Vojinović, Z., Abebe, Y.A., Hammond, M., 2019. Flood Impacts on Road Transportation Using Microscopic Traffic Modelling Techniques, in: Simulating Urban Traffic Scenarios, Lecture Notes in Mobility. Springer, Cham, pp. 115-126. DOI: $10.1007 / 978-3-319-33616-9 \_8$

\section{Introduction}

Floods can impact human activities in many ways and this is why it is common to categorise these impacts. The flood consequences can be grouped as direct or indirect, tangible or intangible, or a combinations of both (Penning-Rowsell et al., 1980). Direct damages occur if the asset of interest is physically exposed to flood waters (i.e., buildings, people or environment). Indirect damages are usually outside the flooded area and usually become apparent after a longer time (Merz et al., 2010). A classic example of indirect losses is the interruption of production in a firm that might occur due to a supplier affected by flooding. Traffic disruption due to floods is another indirect flood impact, the importance of which has not been studied in detail. The main reasons are: 1) the complexity of integrating two highly dynamic and uncertain systems; 2) the need to assess flood impacts in monetary terms (for the purposes of cost-benefit ratio). Flood impacts on traffic are often intangible: loss of time, frustration, environmental degradation due to additional $\mathrm{CO}_{2}$ emissions. However, they can also have monetary dimensions: additional operating costs and fuel consumption have market prices, and loss of time could be monetized as well. Approaches to monetize the intangibles and the emerging importance of multi-criteria analysis for hazard impact assessments create the necessary conditions for the proper evaluation of flood impacts on traffic.

To date traffic disruption due to flooding has received little attention. Comprehensive flood impact guidelines recommend carrying out traffic disruption studies only if the expected traffic losses are significant, because otherwise the cost of traffic disruption is negligible compared to direct or indirect tangible costs (Penning-Rowsell, 2010). However, the importance of impacts on traffic (relative to other flood impacts) varies - in some cities (e.g. Beijing), flooding has exaggerated the problems in their congested transportation network; but in other cities it is not so significant. So far the flood impacts on traffic have been approached using simple mathematical models (Penning-Rowsell, 2010) or macroscopic traffic models (Suarez et al., 2005; Chang et al., 2010). None of these methods considered the dynamics of the transportation system, rerouting whilst a street is closed, or the dynamics of the flooding event. These methods represent a static system, which uses homogeneous aggregated traffic flows. The reliability of such models is not high, especially when it comes to simulating decisions in complex urban traffic networks. Microsimulation represents traffic congestion situations and bottlenecks more realistically, mainly through its algorithms incorporating drivers' responses and intermodal transportation (Helbing et al., 2002; Kerner and Klenov, 2003).

Hitherto micro-simulation has not been used for computing flood impacts on traffic congestion and this is one of the main goals of this research. From the modelling part an evident gap in the current research is the fact that traffic models are not based on the duration and propagation of the flood. The methods introduced in this paper will address this dynamic behaviour of the system, through timely changes of the status of the links (open, closed, or with a certain speed limit in accordance to the changes in flood depth). 
Pyatkova, K., Chen, A.S., Djordjević, S., Butler, D., Vojinović, Z., Abebe, Y.A., Hammond, M., 2019. Flood Impacts on Road Transportation Using Microscopic Traffic Modelling Techniques, in: Simulating Urban Traffic Scenarios, Lecture Notes in Mobility. Springer, Cham, pp. 115-126. DOI: $10.1007 / 978-3-319-33616-9 \_8$

Further improvement in the hydraulic component of the methodology is also desired. The hydraulic models used by Suarez et al. (2005) and Chang et al. (2010) do not simulate surface flooding, caused by insufficient drainage capacity. Hydraulic modelling is a key element in urban flood management (Djordjević et al., 2007; Chang et al., 2015), especially when a realistic representation of flooding on the streets is necessary.

As extreme events are the main cause of flooding, this research is also interested in the impacts of adverse weather conditions on transportation systems. There is no indication that effects of bad weather have been included earlier to model flood impacts on traffic. Heavy rainfall events lead to a reduction in speed and capacity of the network (Keay and Simmonds, 2005; Maze et al., 2006; Koetse and Rietveld, 2009; Cools et al., 2010; Doll et al., 2013; Michaelides, 2014). Keay and Simmonds (2005) found that traffic delays increase with the intensity of precipitation. Smith et al. (2004) estimated that during rainfall events average speed reductions are approximately 5-6.5\%. Nokkala et al. (2012) used another approach to estimate travel delays due to bad weather. Speed reductions of $20 \%, 30 \%$ and 40 $\%$ were assigned to trips with different average speed, assuming shorter trips will have lower average speed than longer trips. This assumption is valid for mathematical models, but it disregards the different road capacities on the network. For the purposes of the methodology in this paper, the speed reduction will be applied as a proportion of maximum speed limit per link in the road network. This will allow vehicles to have varying speed according to their routes.

The connection between rainfall, reduced visibility, increase in reaction time and speed reduction is apparent from drivers' safety viewpoint. On the other hand, adverse weather impacts on traffic demand are more complex, because it might lead to the cancellation of trips or changes in travel modes (Al Hassan and Barker, 1999; Chung et al., 2005; Maze et al., 2006). The feedback to traffic demand will be assessed in the current research by cancelling trips that have origins or destinations in the flooded area.

This paper focuses only on the methodology for integrating flood and road transportation models and results discussion is going to be subject to future work.

\section{Methodology}

The proposed conceptual framework for incorporating flooding conditions into a microscopic traffic model is outlined in Figure 1. As discussed earlier, the impact of extreme hydro-meteorological events on transportation is twofold - coming from rainfall events and flooding of the road network. First, the extreme weather conditions lead to reduced maximum speed limits (Keay and Simmonds, 2005). As different streets in the network have different speed limits, the atmospheric conditions will define a proportionate speed reduction in each link. The decrease of speed limit will be driven by the intensity and the duration of the rainfall event and it will reduce road capacity before the flood has even occurred. Thus, the flood impacts will start evolving in a transportation system, which already has reduced capacity due to heavy rainfall intensities. 
Pyatkova, K., Chen, A.S., Djordjević, S., Butler, D., Vojinović, Z., Abebe, Y.A., Hammond, M., 2019. Flood Impacts on Road Transportation Using Microscopic Traffic Modelling Techniques, in: Simulating Urban Traffic Scenarios, Lecture Notes in Mobility. Springer, Cham, pp. 115-126. DOI: $10.1007 / 978-3-319-33616-98$

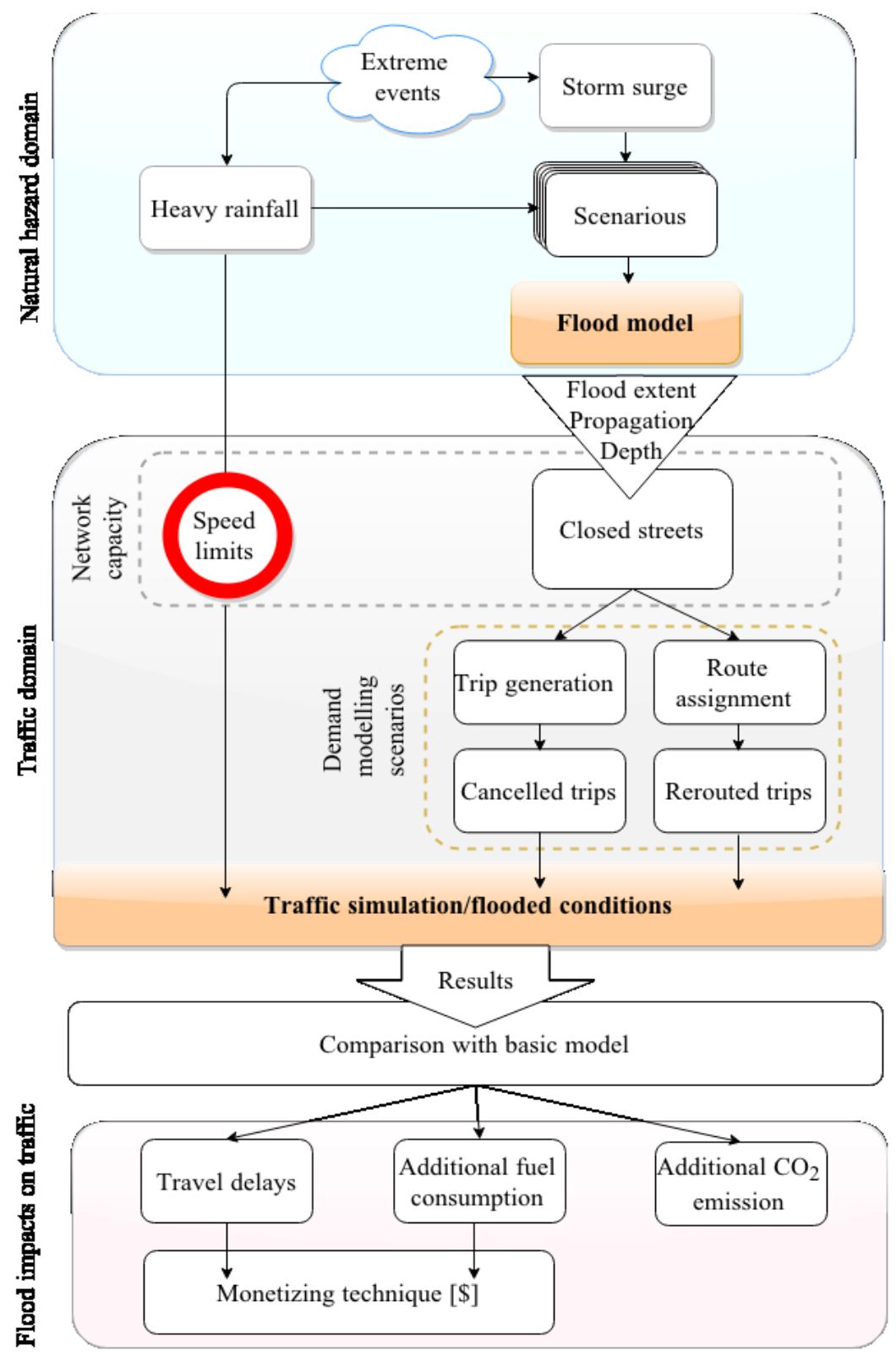

Fig. 1 Flowchart of the proposed methodology

Different combinations of intensities of rainfall and storm surges are simulated to produce the time varying flood characteristics. The consequent flood intensities in terms of flood extent, depth and propagation determine whether a street in the road network is going to be closed for traffic. This closure will affect the overall road capacities, the trip definition and the route assignment components of the flood model. Trips having an origin or destination in the flooded area will be can- 
Pyatkova, K., Chen, A.S., Djordjević, S., Butler, D., Vojinović, Z., Abebe, Y.A., Hammond, M., 2019. Flood Impacts on Road Transportation Using Microscopic Traffic Modelling Techniques, in: Simulating Urban Traffic Scenarios, Lecture Notes in Mobility. Springer, Cham, pp. 115-126. DOI: $10.1007 / 978-3-319-33616-9 \_8$

celled and the routes that pass through a flooded area will be rerouted to unfavourable routes.

The rerouting process assumes that drivers have no initial information that a part of their route has been flooded. Their route diversion is done when they approach the link closed for traffic and then a new route is assigned based on the shortest path to their destination.

A micro-simulation technique facilitates a better and a more detailed representation of the traffic processes, compared to macro-simulation. There are several reasons to adopt a micro-simulation technique for the assessment of flood impacts:

- When a street is closed due to flooding, each vehicle will be rerouted individually, according to its destination. Hence, the rerouting algorithm ensures a detailed representation of the traffic condition during flooded conditions. This is particularly important if there are numerous flooded streets throughout the whole network;

- The micro-simulation technique is more reliable for estimating losses, related to the trips that are cancelled due to flooding because it contains a detailed description of each trip and its purpose;

- The intermodal representation of different vehicle types is important for the overall consumption of fuel and greenhouse gas emissions. Different modes of transportation also indicate different cost of travel delays and will result in a more realistic representation of the flood impacts.

- Microscopic traffic models can simulate the dynamics of the flood propagation both in spatially and temporally. For instance, depending on the flood severity, it can allow closure of only one lane, whist keeping the traffic active in other lanes;

The results of the traffic simulations will be compared for scenarios with and without flooding. The whole procedure will be performed for different flooding scenarios, different times of the day (peak and off-peak times). As stated before the results will be presented in absolute measures of lost business hours, additional fuel consumption, and additional $\mathrm{CO}_{2}$ emissions. The travel delays and the additional fuel consumption will be also represented in monetary terms so that they can be easily compared to the other type of flood losses and damages in the studied area. Ultimately, such an approach will allow the effects of both flood risk management measures and of traffic improvement systems to be tested.

The model will be applied to a case study on a Caribbean island - St Maarten. This case study is considered appropriate for the research for two reasons: first, it has been a frequent victim of tropical storms and hurricanes; second, the closed road network system of an island makes it easier to assess indirect impacts.

The following sections elaborate the hydraulic model, used to simulate the flooding conditions, the translation of flooding results into SUMO environment and the SUMO modelling setup. 
Pyatkova, K., Chen, A.S., Djordjević, S., Butler, D., Vojinović, Z., Abebe, Y.A., Hammond, M., 2019. Flood Impacts on Road Transportation Using Microscopic Traffic Modelling Techniques, in: Simulating Urban Traffic Scenarios, Lecture Notes in Mobility. Springer, Cham, pp. 115-126. DOI: $10.1007 / 978-3-319-33616-9 \_8$

\subsection{Hydraulic model}

The case study area of St Maarten is prone to tropical storms and hurricanes. Even small scale floods in the past posed a serious threat to traffic (UNDP, 2012). The insufficient drainage capacity or the lack of drainage structures results in considerable flood depth on the streets during severe storm events (UNDP, 2012). The hydraulic modelling has been carried out on a catchment level for the most hazardous catchments in the island of St Maarten. The flood hazard characteristics (depth and velocity) were computed using DHI software MIKE FLOOD (DHI, 2007). This software ensures full dynamic coupling between MIKE 11 (1D river model) and MIKE 21 (2D model, computing the flood plain and the coastal flooding). The results from the coastal flooding model were used as boundary conditions in the MIKE FLOOD simulation. Thus, surface runoff and coastal conditions were integrated at each time step. The flooding conditions were simulated for different return periods of storm events, assuming independence of the rainfall and storm surge occurrence. The results of the hydraulic model provided maps for relevant flood depth over time, depending on the flood propagation at a particular site.

\subsection{Translation of flood model results into SUMO model input}

The time varying flood maps identify the streets that will be closed and the duration of the closure. This extraction was performed in a GIS environment by overlaying the flood map with a road network (Figure 2). The roadmap is a modified version of Open Street Map (OSM), which ensures all street types and their corresponding speed limits are correct. In OSM format each street is defined by its ID and this is not suitable for the purposes of a precise identification of flood locations. The desired level of precision requires each edge of the network to have a unique ID, which can be identified by the traffic model. In order to avoid conversion discrepancies, a reliable translation of the link indices was required. This was performed first by segregating major streets into edges in a GIS environment and by giving unique indices of the individual edges. The resultant shapefile was saved as an OSM and then translated to a network file, readable by SUMO. That way, no data will be lost in conversion, i.e. space varying speed limits, or the number of lanes per street. By ensuring same edge IDs, a linkage between the ArcGIS and SUMO environments was established. Thus, a list of flooded streets was identified by their IDs in GIS environment and was readily available for rerouting in SUMO. To provide consistency, the newly created roadmap was used for simulating traffic for the baseline scenario as well as the various flooding scenarios.

The criterion for a street closure was based on flood characteristics - extent, propagation, depth and velocity. Guidelines for a street closure can be found in studies related to car stability in flood water. Stationary vehicle stability in flood waters has been an object of experimental (Teo et al., 2012) and analytical studies 
Pyatkova, K., Chen, A.S., Djordjević, S., Butler, D., Vojinović, Z., Abebe, Y.A., Hammond, M., 2019. Flood Impacts on Road Transportation Using Microscopic Traffic Modelling Techniques, in: Simulating Urban Traffic Scenarios, Lecture Notes in Mobility. Springer, Cham, pp. 115-126. DOI: $10.1007 / 978-3-319-33616-9 \_8$

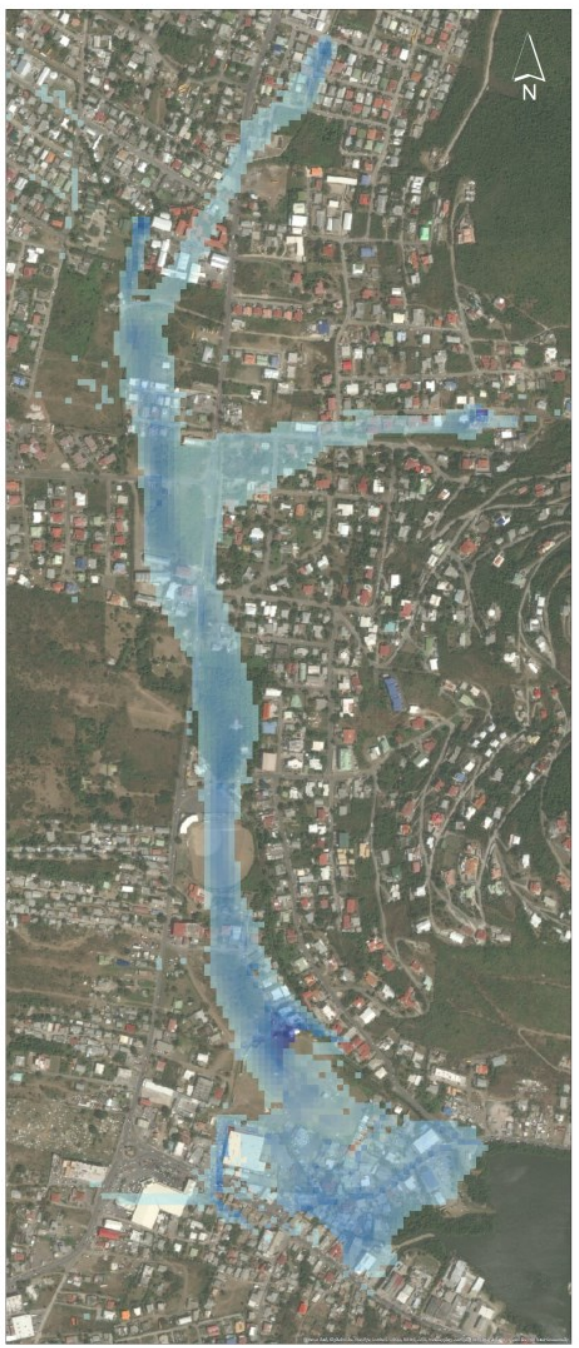

$\begin{array}{lll}0 & 0.125 & 0.25\end{array}$

Flood depth [m]

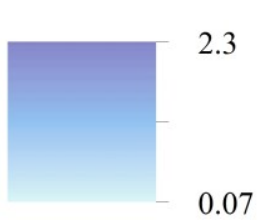

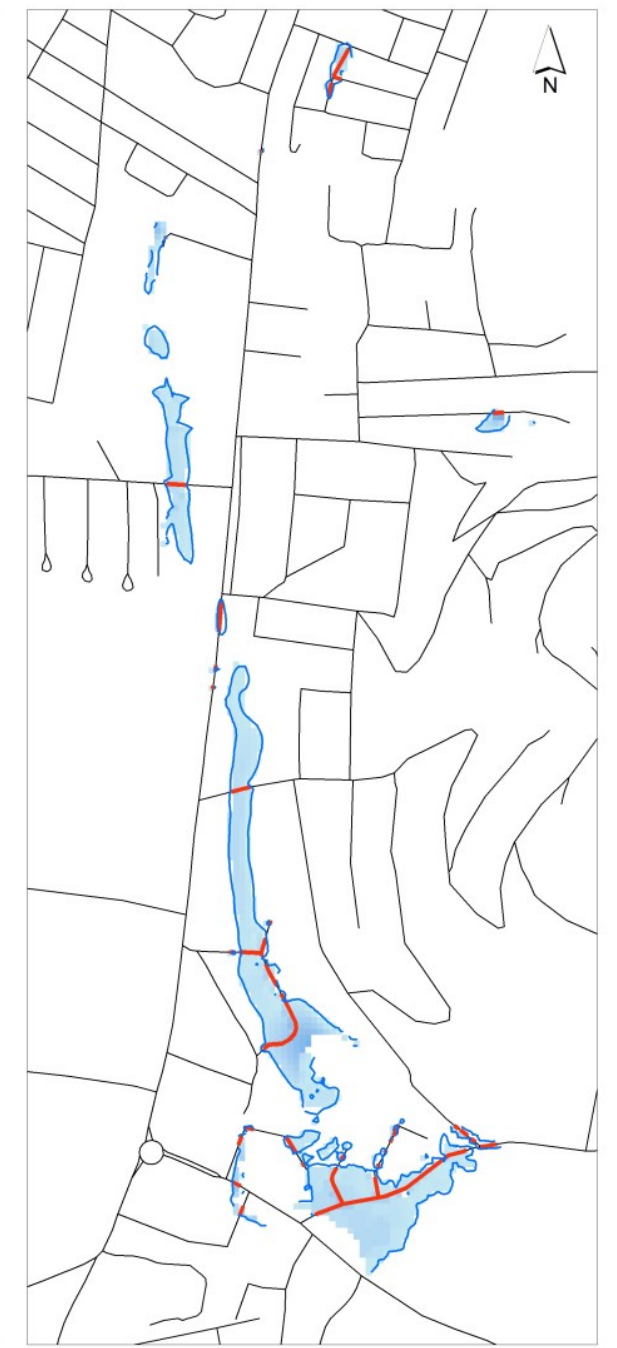

0.75

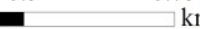

\section{$\mathrm{m}$}

Flood depth above $0.3 \mathrm{~m}$

_ Road Network

Flooded streets *

* Definition of a flooded street water depth above $0.3 \mathrm{~m}$

Fig. 2 Flood map with 100 years return period of a rainfall event (left), and a road map overlaid with a flood map with flood depth above $0.3 \mathrm{~m}$ (right), showing in red the roads closed to traffic 
Pyatkova, K., Chen, A.S., Djordjević, S., Butler, D., Vojinović, Z., Abebe, Y.A., Hammond, M., 2019. Flood Impacts on Road Transportation Using Microscopic Traffic Modelling Techniques, in: Simulating Urban Traffic Scenarios, Lecture Notes in Mobility. Springer, Cham, pp. 115-126. DOI: 10.1007/978-3-319-33616-9_8

(Keller and Mitsch, 1992). Shand et al. (2011) carried out a literature review for the purpose of establishing guidelines for vehicle safety on the road. They found a considerable agreement among the literature about the floating limits of different types of vehicles - small passenger $(0.3 \mathrm{~m})$, large passenger $(0.4 \mathrm{~m})$ and 4DW $(0.5$ $\mathrm{m})$. These guidelines were adopted in the current research as a rule for a road closure: streets with more than $0.3 \mathrm{~m}$ flood depth were closed for traffic.

\subsection{SUMO parameters setting and traffic volume estimation}

The SUMO software (Behrisch et al., 2011) has been used to create a basic model, so that the proposed methodology can be tested (Figure 3). The traffic model was limited by the reduced availability of transportation measurement data, but it is believed there are sufficient data to further test the methodology. Currently the model uses the traffic network of the whole island of St Maarten, which is rather large for conventional microsimulation network (total area $87 \mathrm{~km}^{2}$ and nearly 80000 inhabitants).

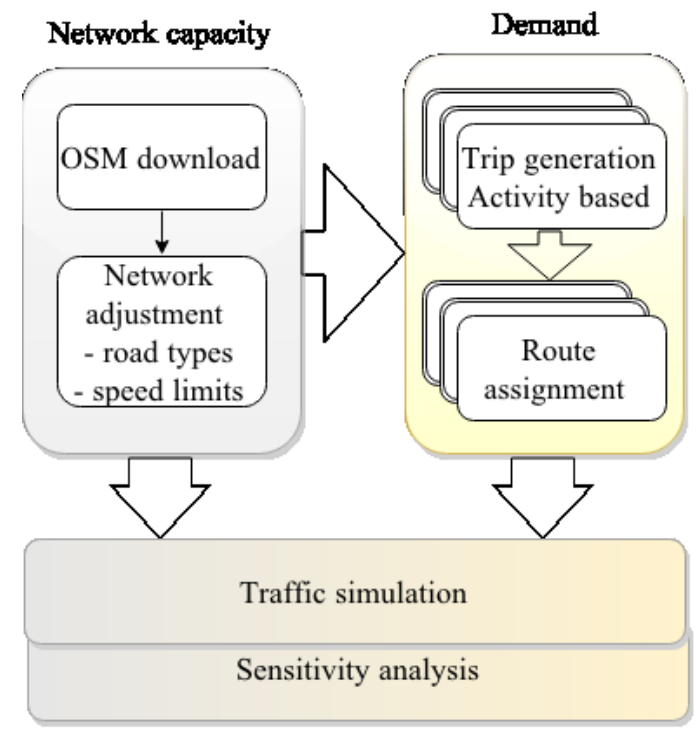

Fig. 3 Flowchart of the implemented traffic model

This network has been extracted from OSM and later on modified for the applications in SUMO, with special attention given to the different types of roads and their maximum speed limits. The traffic demand was established on a quasirandom route generation (ActivityGen), based on statistics about settlements, population and the locations of big employers and schools. Different parameter combinations were used to run the model and obtain statistics for each scenario. The 
Pyatkova, K., Chen, A.S., Djordjević, S., Butler, D., Vojinović, Z., Abebe, Y.A., Hammond, M., 2019. Flood Impacts on Road Transportation Using Microscopic Traffic Modelling Techniques, in: Simulating Urban Traffic Scenarios, Lecture Notes in Mobility. Springer, Cham, pp. 115-126. DOI: $10.1007 / 978-3-319-33616-9 \_8$

route assignment of the current model employs shortest path algorithm to establish a route between the origin and the destination of each trip. For a better representation of route choices an algorithm representing shortest travel time is required.

Sensitivity analysis of different scenario results can help improve the understanding of how the system functions. This strategy for computing traffic demand was hoped to help overcome the lack of data for calibration. A large number of quasi-randomly generated data approaches the traffic demand distribution from a probabilistic standpoint.

Another objective of the research is to investigate what the environmental impact of traffic congestion during floods can be. To achieve this, the SUMO model employed a simplified HBEFA classification of vehicles and their relevant $\mathrm{CO}_{2}$ emission levels for different engines. This model also provides a description of fuel consumption for individual trips in the simulation and thus can help monetize the impacts of floods on traffic congestion.

\subsection{Monetization of traffic delays}

Previous studies in the field of flood impacts on traffic congestion (Chang et al., 2010; Suarez et al., 2005) indicated that wasted time will be the most significant impact. This imposes the need to monetize business hours lost in traffic, so that they can be compared to other tangible flood impacts such as damage to builtenvironment or business interruption. Value of time per individual person (driver or passenger) is defined by the purpose of the trip, mode of transportation and the type of vehicle (Vickerman, 2000). Monetizing of travel time has been approached using wage data to assign monetary values per hour for different trip purposes business, commute or leisure (Tervonen et al., 2010). The cost of the additional travel time can also depend on the duration of the delay. Interviews showed delays longer than $30 \mathrm{~min}$ have higher relative costs than shorter delays (Douglas et al., 2003). This research will employ a monetizing method which will consider a UK methodology (Vickerman, 2000) to estimate costs of travel times based on assumptions on average income.

\section{Modelling challenges and future improvements}

We have created a preliminary model to test the proposed methodology. The trial has shown several challenges to be solved. Trivial setbacks like data conversion issues are typical when integrating models with very different inputs and outputs. The rerouting mechanisms, employed to represent street closure, are originally established to simulate traffic incidents on the road. They require an individual set up, which is not trivial, when a large number of streets have to be closed due to the flooded conditions. For example, when $30 \mathrm{~cm}$ of flood depth was 
Pyatkova, K., Chen, A.S., Djordjević, S., Butler, D., Vojinović, Z., Abebe, Y.A., Hammond, M., 2019. Flood Impacts on Road Transportation Using Microscopic Traffic Modelling Techniques, in: Simulating Urban Traffic Scenarios, Lecture Notes in Mobility. Springer, Cham, pp. 115-126. DOI: $10.1007 / 978-3-319-33616-98$

used as a criterion for street closure, 268 streets in the whole network were identified to be closed and the traffic through them should be rerouted. From a traffic modelling point of view, the road network was going to suffer from 268 accidents, whose temporal characteristics depended on the propagation of the flood. In SUMO terms, each of these accidents had to be represented independently and this posed a problem when multiple scenarios were going to be modelled and discussed. As mentioned previously, the main objective of the current research is the development of a tool for the integration of flood and traffic models. Such a tool will eliminate drawbacks like the file conversion or multiple file creation for different purposes of the modelling process.

Due to the lack of traffic data, modelling different vehicle classes and purposes of trips are reliant purely on assumptions. However, different vehicle classes can give valuable input, when traffic delays or cancellation of trips are monetized. This is currently represented by the activity-based traffic demand model, which generates trips according to synthetic data about population and locations of big employers, schools and shops. Similarly, modelling emergency vehicles such as ambulances or fire brigade vehicles is very important in times of disaster management. For example, the hospital in Philipsburg in St. Maarten can be reached only by one road which is prone to flooding. Evaluation of flood impacts like these is a great challenge because losses are intangible and are no longer related to the particularities of the traffic conditions.

\section{Concluding remarks}

This paper presents a novel methodology for assessing flood impacts on traffic. Micro-simulation traffic models have not been used yet to approach that problem, even though only a microsimulation model can capture the dynamics of both the natural and social-technological sphere. The impacts of adverse weather conditions on traffic have been studied in detail but have never been previously incorporated with flood events. This methodology combines the joint impacts of both adverse weather conditions and accumulated floods to road transportation.

The methodology presented in this paper will be implemented in real world applications. The actual traffic measurements will be applied to calibrate the parameters used in the SUMO to ensure the modelling results can represent the traffic conditions properly. Cost assessment model of travel delays also needs to be adjusted to regional specifications of salaries in Saint Martin.

This interdisciplinary approach relates to off-line analysis of combined flood and traffic modelling. The methodology lends itself nicely for real-time modelling and decision making for coupled flood and traffic management systems.

\section{Acknowledgment}

Research on the PEARL (Preparing for Extreme And Rare events in coastaL regions) project is funded by the European Commission through Framework Programme 7, Grant Number 603663 . 
Pyatkova, K., Chen, A.S., Djordjević, S., Butler, D., Vojinović, Z., Abebe, Y.A., Hammond, M., 2019. Flood Impacts on Road Transportation Using Microscopic Traffic Modelling Techniques, in: Simulating Urban Traffic Scenarios, Lecture Notes in Mobility. Springer, Cham, pp. 115-126. DOI: $10.1007 / 978-3-319-33616-9 \_8$

\section{References}

Al Hassan, Y., Barker, D.J., 1999. The impact of unseasonable or extreme weather on traffic activity within Lothian region, Scotland. J. Transp. Geogr. 7, 209-213. doi:10.1016/S0966-6923(98)00047-7

Behrisch, M., Bieker, L., Erdmann, J., Krajzewicz, D., 2011. SUMO - Simulation of Urban MObility - an Overview. Presented at the SIMUL 2011, The Third International Conference on Advances in System Simulation, pp. 55-60.

Chang, H., Lafrenz, M., Jung, I.-W., Figliozzi, M., Platman, D., Pederson, C., 2010. Potential Impacts of Climate Change on Flood-Induced Travel Disruptions: A Case Study of Portland, Oregon, USA. Ann. Assoc. Am. Geogr. 100, 938-952. doi:10.1080/00045608.2010.497110

Chang, T.-J., Wang, C.-H., Chen, A.S., 2015. A novel approach to model dynamic flow interactions between storm sewer system and overland surface for different land covers in urban areas. J. Hydrol. 524, 662-679. doi:10.1016/j.jhydrol.2015.03.014

Chung, E., Ohtani, O., Warita, H., Kuwahara, M., Morita, H., 2005. Effect of rain on travel demand and traffic accidents, in: 2005 IEEE Intelligent Transportation Systems, 2005. Proceedings. Presented at the 2005 IEEE Intelligent Transportation Systems, 2005. Proceedings, pp. 1080-1083. doi:10.1109/ITSC.2005.1520201

Cools, M., Moons, E., Wets, G., 2010. Assessing the Impact of Weather on Traffic Intensity. Weather Clim. Soc. 2, 60-68. doi:10.1175/2009WCAS1014.1

DHI, 2007. MIKE FLOOD Modelling of Urban Flooding, A Step-by-step training guide.

Djordjević, S., Chen, A., Leandro, J., Savić, D., Boonya-aroonnet, S., Maksimović, Č., Prodanović, D., Blanksby, J., Saul, A., 2007. Integrated sub-surface/surface 1D/1D and 1D/2D modelling of urban flooding. Proc. Aquaterra World Forum Delta Coast. Dev.

Doll, C., Trinks, C., Sedlacek, N., Pelikan, V., Comes, T., Schultmann, F., 2013. Adapting rail and road networks to weather extremes: case studies for southern Germany and Austria. Nat. Hazards 72, 63-85. doi:10.1007/s11069-013-0969-3

Douglas, N.J., Franzmann, L.J., Frost, T.W., 2003. The estimation of demand parameters for primary public transport service in Brisbane attributes, in: Australasian Transport Research Forum (ATRF), 26th, 2003, Wellington, New Zealand.

Helbing, D., Hennecke, A., Shvetsov, V., Treiber, M., 2002. Micro- and macro-simulation of freeway traffic. Math. Comput. Model. 35, 517-547. doi:10.1016/S08957177(02)80019-X

Keay, K., Simmonds, I., 2005. The association of rainfall and other weather variables with road traffic volume in Melbourne, Australia. Accid. Anal. Prev. 37, 109-124. doi:10.1016/j.aap.2004.07.005

Keller, R.J., Mitsch, B.F., 1992. Stability of Cars and Children in Flooded Streets [WWW Document].

URL http://search.informit.com.au/documentSummary;dn=696127213419517;res=IELENG (accessed 1.5.15).

Kerner, B.S., Klenov, S.L., 2003. Microscopic theory of spatial-temporal congested traffic patterns at highway bottlenecks. Phys. Rev. E 68, 036130. doi:10.1103/PhysRevE.68.036130 
Pyatkova, K., Chen, A.S., Djordjević, S., Butler, D., Vojinović, Z., Abebe, Y.A., Hammond, M., 2019 Flood Impacts on Road Transportation Using Microscopic Traffic Modelling Techniques, in: Simulating Urban Traffic Scenarios, Lecture Notes in Mobility. Springer, Cham, pp. 115-126. DOI: $10.1007 / 978-3-319-33616-9 \_8$

Koetse, M.J., Rietveld, P., 2009. The impact of climate change and weather on transport: An overview of empirical findings. Transp. Res. Part Transp. Environ. 14, 205-221. doi:10.1016/j.trd.2008.12.004

Maze, T., Agarwai, M., Burchett, G., 2006. Whether Weather Matters to Traffic Demand, Traffic Safety, and Traffic Operations and Flow. Transp. Res. Rec. J. Transp. Res. Board 1948, 170-176. doi:10.3141/1948-19

Merz, B., Kreibich, H., Schwarze, R., Thieken, A., 2010. Review article "Assessment of economic flood damage.” Nat Hazards Earth Syst Sci 10, 1697-1724. doi:10.5194/nhess10-1697-2010

Michaelides, S., 2014. Vulnerability of transportation to extreme weather and climate change. Nat. Hazards 72, 1-4. doi:10.1007/s11069-013-0975-5

Nokkala, M., Leviäkangas, P., Oiva, K., 2012. The costs of extreme weather for the European transpor tsystems (No. EWENT project D4).

Penning-Rowsell, E., 2010. The benefits of flood and coastal risk management: a manual of assessment techniques / Edmund Penning-Rowsell ... [et al.]. : Middlesex University Press, London.

Penning-Rowsell, E., Chatterton, J., Rowsell, E.P., 1980. Assessing benefits the of flood alleviation and land drainage schemes. ICE Proc. 69, 295-315. doi:10.1680/iicep.1980.2539

Shand, T.D., Smith, G.P., Cox, R.J., Blacka, M., 2011. Development of Appropriate Criteria for the Safety and Stability of Persons and Vehicles in Floods [WWW Document]. URL http://search.informit.com.au/documentSummary;dn=317612923491163;res=IELENG (accessed 1.6.15).

Smith, B.L., Byrne, K.G., Copperman, R.B., Hennessy, S.M., Goodall, N.J., 2004. An investigation into the impact of rainfall on freeway traffic flow, in: 83rd Annual Meeting of the Transportation Research Board, Washington DC.

Suarez, P., Anderson, W., Mahal, V., Lakshmanan, T.R., 2005. Impacts of flooding and climate change on urban transportation: A systemwide performance assessment of the Boston Metro Area. Transp. Res. Part Transp. Environ. 10, 231-244. doi:10.1016/j.trd.2005.04.007

Teo, F.Y., Xia, J., Falconer, R.A., Lin, B., 2012. Experimental studies on the interaction between vehicles and floodplain flows. Int. J. River Basin Manag. 10, 149-160. doi:10.1080/15715124.2012.674040

Tervonen, J., Ristikartano, J., Penttinen, M.-M., 2010. Tieliikenteen ajokustannusten yksikköarvojen määrittäminen. Liikenneviraston Tutkimuksia Ja Selvityksiä 33, 2010.

UNDP, 2012. Innovation and technology in risk mitigation and development planning in SIDS: Towards flood risk reduction in Sint Maarten. United Nations Development Programme, Barbados and the OECS.

Vickerman, R., 2000. Evaluation methodologies for transport projects in the United Kingdom. Transp. Policy 7, 7-16. doi:10.1016/S0967-070X(00)00009-3 